\title{
PEMODELAN KONTINU 2-D BERBASIS EFEK ELEKTOKINETIK DENGAN FINITE ELEMENT PENDEKATAN GALERKIN
}

\author{
Delia Meldra ${ }^{*}$ \\ ${ }^{1}$ Progam Studi Teknik Industri Universitas Putera Batam, \\ Jalan R. Soeprapto, Muka Kuning, Batam, Kepulauan Riau \\ *Email: dmeldra@gmail.com
}

\begin{abstract}
Method refers to a measurement of naturally electric potential on the surface. Self Potential is one of the geophysical methods that can be used to identify fluid flow in the subsurface. Finite element method has been used to fluid flow velocity modeling, current source, and potential distribution modeling based on electrokinetic effect in 2-D profile. The sign of potensial respon (negative or positive) is an important factor for the interpretation of self-potential anomalies. Finite element method is one of the numerical methods for solve the boundary value problems and the boundary conditions in the form of differential equations in SelfPotential modeling.
\end{abstract}

Keywords: Electric Current Source, Finite Element Method, Boundary Condition, Topography

\section{Pendahuluan}

Metode Self-Potential merupakan pengukuran perbedaan potensial alami pada permukaan bumi. Metode Self-Potential pertama kali diprakasai oleh Robert Fox pada tahun 1830 (Reynolds, 1997) dengan menggunakan elektroda lempeng tembaga yang dihubungkan dengan Galvanometer untuk mendeteksi cadangan sulfida-tembaga di CornWall, Inggris. Metode ini digunakan sejak tahun 1920 sebagai peralatan alternatif pada eksplorasi logam. Metode SelfPotential telah banyak digunakan untuk eksplorasi sulfida (Sato dan Mooney, 1960), anomali Self-Potential pada gunung api (Zlotnicki, 2003), Groundwater (Kim, 2004), aliran dangkal air tanah (A. Jardani, 2006), daerah prospek geotermal (Yasukawa, 2000), daerah terkontaminasi minyak (Zogala, 2012).

Anomali Self-Potential dapat dihasilkan oleh mekanisme difusi dan membran, potensial bioelektrik, streaming potensial, dan potensial mineral (Telford, 1990). Potensial streaming (potensial elektrokinetik) berkaitan dengan aliran air tanah dan fluida lainnya yang mengandung elektrolit melalui patahan atau pengeroposon. Metode Self-Potential dipakai untuk eksplorasi panas bumi, hal ini disebabkan karena metode ini dapat menggambarkan aliran fluida pada gunung api yang berguna untuk menentukan posisi dari sumber panas (Yasukawa, 2003). Adapun jangkauan kedalamannya sekitar $1500 \mathrm{~m}$. Anomali Self-Potential dapat berkisar dari milivolt (mV) sampai 1 Volt, dengan tanda negatif ataupun positif.

Analisa terhadap metode Self-Potential dapat dilakukan dengan pemodelan. Terdapat dua tipe pemodelan itu pemodelan kedepan dan inverse. Pemodelan kedepan merupakan pemodelan yang dilakukan untuk memperoleh respon dari model yang dibuat berdasarkan sifat-sifat fisis yang diketahui.

Pada penelitian ini dilakukan pemodelan dari metode Self-Potential dengan menggunakan teknik finite element untuk mendapatkan respon Self-Potential dipermukaan karena pengaruh aliran sebagai salah satu sumber alami dari SelfPotential, serta pengaruh kondisi geologi atau topografi. Teknik finite element merupakan salah satu teknik numerik yang digunakan untuk menyelesaikan persamaan diferensial dengan persoalan syarat batas (Boundary Value Problem) dan menerapkan syarat batas (Polycarpou, 2006). Ada beberapa pendekatan teknik finite element salah satunya yaitu pendekatan galerkin yang digunakan pada penelitian ini.

Tujuan melakukan penelitian ini adalah memodelkan respon Self-Potential dalam bentuk profil 2-D dengan menghadirkan aliran sebagai sumber alami dari Self-Potential dan dapat melihat respon yang berbasis efek elektrokinetik.

\section{Landasan Teori}




\subsection{Self-Potential}

Metode ini disebut Self-Potential karena potensial yang dihasilkan oleh sejumlah sumber alami dari bumi tanpa adanya injeksi ke bawah permukaan bumi. Nilai beda potensial yang terukur dipermukaan kurang dari milivolt hingga satu volt, serta tanda (negatif atau positif) dari potensial yang didapat merupakan faktor penting untuk interpretasi anomali Self-Potential. Metode ini biasanya untuk eksplorasi dangkal, sekitar 100 $\mathrm{m}$, akan tetapi dalam domain pemodelan bisa mencapai $1,5 \mathrm{~km}$. Anomali Self-Potential dapat dihasilkan oleh mekanisme difusi dan membran, potensial bioelektrik, streaming potensial, dan potensial mineral (Telford, 1990). Difusi dan potensial membran terkait dengan kosentrasi gradien dan pergerakan ion dibawah permukaan yang menghasilkan beda potensial listrik. Pemompaan air dan filtrasi ion oleh akar tanaman akan menghasilkan potensial bioelektrik. Potensial streaming (potensial elektrokinetik) berkaitan dengan aliran air tanah dan fluida lainnya yang mengandung elektrolit melalui patahan.

\subsection{Potensial Elektrokinetik}

Potensial streaming terbentuk ketika aliran fluida melewati permukaan biji mineral yang mengandung muatan negatif. Sehingga muatan positif dari fluida akan berinteraksi dan berakumulasi permukaan biji mineral, membentuk lapisan yang disebut lapisan lisrik rangkap (electrical double layer), yang mana ionionnya terikat. Lapisan ini terdiri dari lapisan dalam yang disebut Stem internal di mana muatan negatif di permukaan biji mineral menarik dan mengikat ion positif dari fluida langsung pada permukaan biji mineral, dan lapisan difusi dimana sisa ion positif dari fluida tertarik tapi tidak langsung menempel ke permukaan biji mineral.

\subsection{Potensial Termoelektrik}

Potensial termoelektrik terjadi saat gradien temperatur melewati sampel batuan maka akan menghasilkan medan listrik. Ini disebabkan oleh perbedaan difusi termal dari ion-ion pada pori fluida serta dari elektron-elektron dan ion pada batuan. Aliran panas terkopel dan rapat arus listrik yang diakibatkan oleh driving force, yaitu gradien potensial dan gradien temperatur.

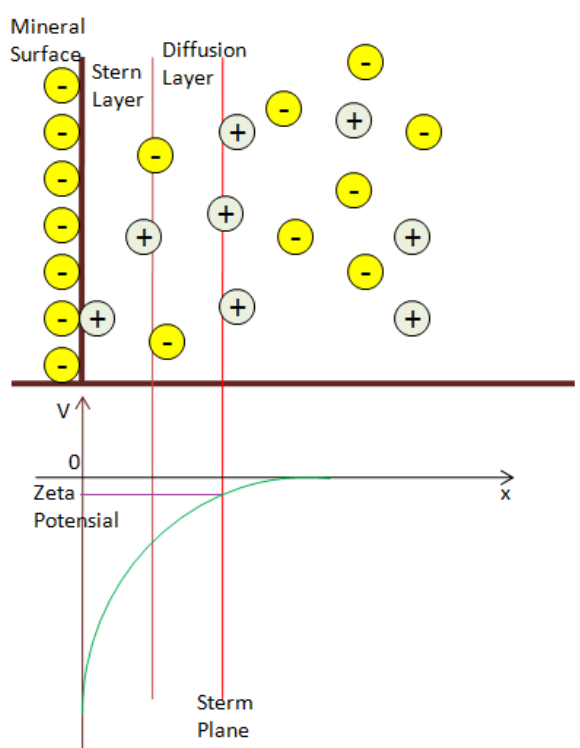

Gambar 1. Lapisan Lisrik Rangkap Pada Batas Antara Biji Mineral Dan Fluida Sumber: redrawn Kim, 2004

\subsection{Potensial Elektrokimia}

Potensial difusi (Liquid Junction) secara transien dapat mencapai puluhan $\mathrm{mV}$ yang disebabkan oleh perbedaan pada mobilitas dari elektrolit-elektrolit yang mempunyai kosentrasi berbeda pada air tanah. Sedangkan potensial Nernst (shale) terjadi ketika terdapat perbedaan potensial antara dua elektroda yang dicelupkan pada larutan homogen dimana kosentrasi dari larutan berbeda. Potensial Nernst merupakan kasus khusus dari potensial difusi. Potensial elektrokimia merupakan kontribusi dari potensial dan potensial Nernst.

\subsection{Potensial Mineral}

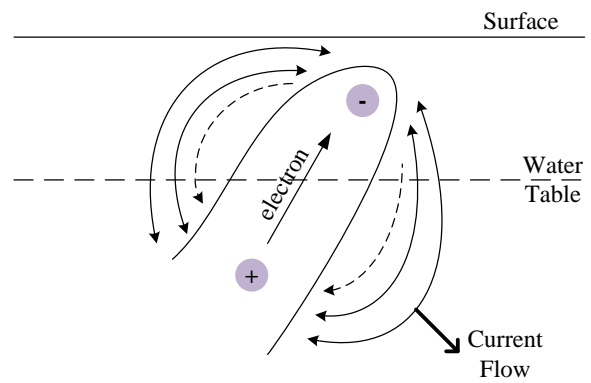

Gambar 2. Mekanisme dari Anomali SelfPotential

Sumber: Sato dan Mooney, 1960

Berdasarkan Gambar II, Model Sato dan Mooney (1960) memberikan gambaran mengenai potensial mineral, walaupun belum ada hipotesa yang bisa mencakup seluruh mineral yang teramati. Ketika bagian bijih berada di atas permukaan air tanah terbentuk katoda sebagai hasil reduksi ion disekeliling elektrolit sehingga 
memerlukan elektron. Sebaliknya di bawah permukaan air tanah terbentuk anoda dimana oksidasi lebih dominan dan ion kehilangan elektron-elektronnya. Peran dari bijih mineral adalah meneruskan aliran elektron dari bagian bawah ke bagian atas, sehingga hasilnya bagian atas permukaan menjadi lebih negatif (menjadi anomali negatif pada pengukuran metode SelfPotential) dan bagian bawah menjadi positif.

\subsection{Hukum Darcy}

Prinsip empiris aliran air tanah, dalam persamaan dikenal sebagai hukum Darcy.

$$
\vec{v}=-\frac{k}{\eta} \nabla P
$$

\section{Metodologi Penelitian}

\subsection{Teknik Pengumpulan Data}

Penelitian ini menggunakan pendekatan observasi dan literature untuk membantu mengumpulkan infomasi penelitian. Observasi bertujuan untuk memperoleh informasi langsung hasil pengujian model penelitian. Sedangkan literature digunakan untuk menggali informasi dari pemodelan.

\subsection{Metode Analisis Data}

Teknik finite element merupakan salah satu teknik numerik yang digunakan untuk menyelesaikan persamaan diferensial dengan persoalan syarat batas (Boundary Value Problem) dan menerapkan syarat batas (Polycarpou, 2006). Metoda ini membagi suatu domain dengan subdomain yang lebih kecil yang disebut finite element (elemen hingga). Distribusi dari fungsi yang dicari di dalam elemen diinterpolasi berdasarkan nilai pada simpul-simpulnya. Interpolasi atau fungsi bentuk dari elemen haruslah berbentuk polynomial lengkap. Tingkat akurasi bergantung pada bentuk polynomial (seperti linier, kuadratik, atau orde yang lebih tinggi). Solusi numerik berhubungan dengan nilai-nilai fungsi yang dicari pada simpul atau ujung dari diskritisasi domain. Solusi diperoleh setelah menyelesaikan sistem persamaan linier.

Terdapat dua pendekatan yang cukup sering digunakan untuk memperoleh persamaan pada teknik finite element, yaitu pendekatan variasional dan pendekatan residual terbobot. Pendekatan variasional menggunakan fungsi yang direpresentasikan dari permasalahan Boundary Value Problems. Solusi stasioner fungsi tersebut dihitung pada daerah dengan minimum dan maksimumnya dari fungsi tersebut.
Sedangkan pendekatan Galerkin diawali dengan pembuatan residu secara langsung dari persamaan diferensial yang memiliki Boundary Value Problems (BVP). Pada metoda finite element ini digunakan pendekatan residual terbobot atau disebut pendekatan Galerkin.

Beberapa permasalahan dari persamaan diferensial orde dua dengan variabel bebas yaitu dalam penentuan syarat batas. Untuk mendapatkan solusi yang unik dan spesifik dalam suatu pemodelan diperlukan suatu syarat batas, yaitu syarat batas Dirichlet dan syarat batas Neumann. Syarat batas Dirichlet merupakan syarat batas yang mempunyai nilai spesifik (atau dapat ditentukan nilainya) pada batas domainnya, sedangkan syarat batas Neumann adalah nilai gradient dari turunan solusi pada batas domain (Polycarpou, 2006).

\subsection{Skema Pemodelan}

\section{Pemodelan Aliran}

Melakukan perhitungan nilai fluid head dari aliran mengunakan teknik finite element. Dimana untuk kasus aliran tunak:

$$
\nabla^{2} P=0
$$

\section{Pemodelan Self-Potential}

Total arus listrik yang disebabkan oleh gradien listrik dan gradien hidrolik dideskripikan sebagai berikut:

$$
\vec{J}=-L_{p} \nabla P-\sigma \nabla V
$$

Untuk sifat material persamaan (3) dapat ditulis dengan menghubungkan konsep dari medan kecepatan aliran dan kecepatan cross-coupling (Revil, 1999), total rapat arus listrik JT saat ini $(\mathrm{A} / \mathrm{m} 2)$ dapat ditulis:

$$
\vec{J}=-L_{v} \vec{u}+\sigma \vec{E}
$$

Kecepatan konduktivitas cross-coupling dalam arah aliran horizontal satu dimensi dapat dikonversi dari konduktivitas cross-coupling tekanan dengan konduktivitas hidrolik $K$ (Sill, 1982). Dimana hubungan yang digunakan, yaitu $L_{v}=L_{p} / K$ sumber arus luar (seperti arus elektroda) divergensi dari rapat arus $(\nabla \cdot \vec{J}=0)$ adalah nol. Sehingga persamaan (4) dapat ditulis:

$$
S=\nabla \cdot \sigma \vec{E}=-\left(\nabla L_{v}\right) \cdot \vec{u}-L_{v} \nabla \cdot \vec{u}
$$

Persamaan (5) memastikan sumber arus listrik dapat dihitung jika ada perubahan dalam kecepatan konduktivitas cross-coupling dalam arah aliran fluida $\left(-\nabla L_{v}, u \neq 0\right.$ ). Distribusi 
Self-Potential seluruh domain diperoleh dengan memecahkan persamaan Poisson yang berkaitan dengan semua sumber arus dan nilai-nilai konduktivitas domain:

$$
\nabla^{2} V=-\frac{S}{\sigma}
$$

untuk mendapatkan distribusi serta respon SelfPotential dipermukaan, persamaan diferensial yang diterapkan teknik finite element pendekatan Galerkin yaitu persamaan (6)

\section{Hasil dan Pembahasan}

Setelah mengaplikasikan persamaan SelfPotential (6) kedalam teknik finite element dengan pendekatan Galerkin. Persamaan differensial tersebut diselesaikan menjadi sistem persamaan linier dan menetapkan syarat batas yang digunakan untuk pemodelan. Syarat batas yang diterapkan pada pemodelan ini yaitu syarat batas Dirichlet untuk sisi kiri dan kanan, sedangkan untuk sisi atas (permukaan) dan bawah diterapkan syarat batas Neumann. Kemudian pada pemodelan ini sumber yang digunakan yaitu sumber yang didapat dari mencari fluid head, vektor kecepatan, dan hasil akhirnya berupa sumber arus. Hasil pemodelan ini ditampilkan melalui gambar fluid head, vektor kecepatan, sumber Self-Potential, distribusi sebaran potensial dan respon Self-Potential dipermukaaan yang disebabkan oleh sumber $(\mathrm{A} / \mathrm{m} 3)$.
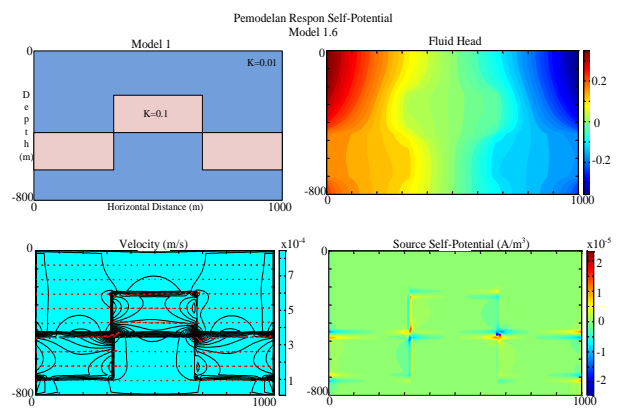

Potential Distribution (N)
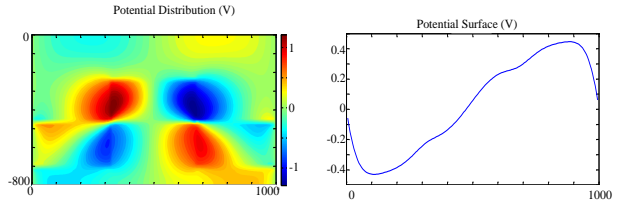

Gambar 3. (a) Kontur fluid head untuk model aliran fluida pada kasus topografi datar dan terdapat patahan ditengah untuk dan $\mathrm{K}$ berbeda. (b) Vektor kecepatan aliran. (c) Sumber arus (A/m3) mengunakan operasi gradien yang melibatkan dan . (d) Distribusi Potensial (V). (e) Respon potensial dipermukaan

Perlakuan yang dilakukan pada model ini yang terlihat pada Gambar III yaitu membentuk lapisan yang menyerupai patahan. Konduktivitas hidrolik pada lapisan ini lebih besar dari sekitarnya. Pada kontur kecepatan aliran terlihat aliran mengalir lebih cepat pada patahan. Respon Self-Potential dipermukaan yang didapat yaitu lebih negatif dikiri dan membentuk lembah pada patahan serta lebih positif dikanan dan membentuk puncak.

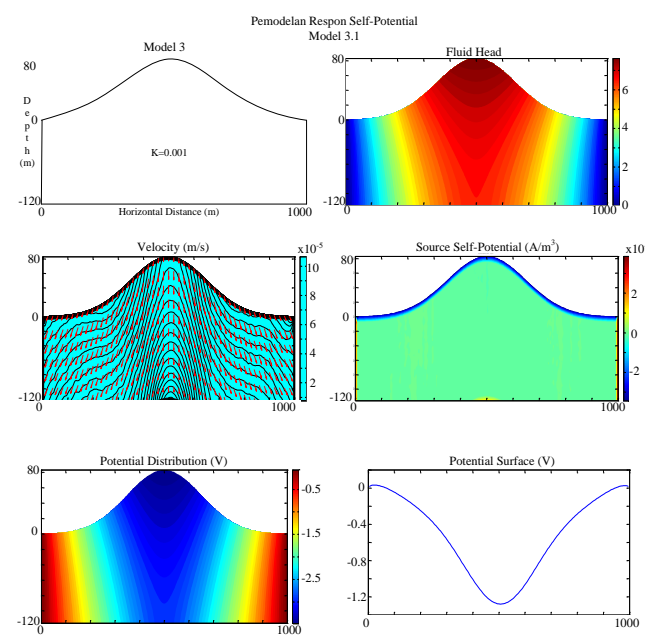

Gambar 4. (a) Kontur fluid head untuk model aliran fluida pada kasus topografi gunung untuk dan K homogen. (b) Vektor kecepatan aliran. (c) Sumber arus (A/m3) mengunakan operasi gradien yang melibatkan dan . (d) Distribusi Potensial (V). (e) Respon potensial dipermukaan

Pada model Gambar IV yaitu domain yang menyerupai gunung, perlakuan pertama yang dilakukan pada model ini yaitu aliran mengalir dari atas keluar ke kiri dan kanan, lapisan dibuat homogen. Respon Self-Potential dipermukaan yang didapat yaitu lebih negatif dari dipuncak gunung dan lebih positif dibagian kiri dan kanan. Model homogen ini juga dapat digunakan sebagai validasi bahwa model yang digunakan sudah benar.

\section{Kesimpulan}

Berdasarkan pemodelan yang telah dilakukan dapat dikemukakan secara khusus kesimpulan dari penelitian ini dilihat sebagai berikut:

1) Telah dilakukan pemodelan Self-Potential dengan menggunakan teknik finite element. Sebaran potensial Self-Potential yang dimodelkan sesuai dengan nilai potensial yang diperkirakan sekitar $\mathrm{mV}$ sampai $1 \mathrm{mV}$,pada saat nilai sumber masih diasumsikan.

2) Telah dilakukan pemodelan vektor kecepatan aliran sebagai bagian dari sumber dengan 
menggunkan finite element, dan telah berhasil diterapkan pada pemodelan Self-Potential.

3) Pemodelan pada topografi datar dengan aliran dari kiri dan kanan, serta dilakukan beberapa perlakuan pada lapisan memperlihatkan bentuk respon yang berbeda.

4) Aliran dari kiri ke kanan menghasilkan respon yang negatif dikiri dan lebih positif dikanan.

5) Pemodelan dengan bentuk topografi gunung memperlihatkan respon yang berkebalikan dengan bentuk topografinya, yaitu pada puncak gunung respon yang didapat negatif, dan pada sisi kiri dan kanan lebih positif.

\section{DAFTAR REFERENSI}

W. M. Telford, Applied Geophysics Second Edition, Cambridge University Press, Australia, 1990

S. Kim, G. Heinson, and J. Joseph, Electrokinetic Ground Water Exploration: a New Geophysical Technique, in Roach I.C. ed. Regolith 2004. CRCLEME, pp. 181185,2004

J. E. Nyuquist and C. E. Corry, Self-Potential: The ugly Duckling of Environmental Geophysics, The Leading Edge, 446-451, 2002

J. Zlotnicki and Y. Nishida. Review on Morphological Insights of Self-Potential Anomalies Volcanoes, Division of Earth and Planetary Sciences, Graduate School of Science, Hokaido University, 2003

Yasukawa, K., Mogi T, Widarto. D, Ehara. S. Numerical Modelling of Hydrothermal Around Waita Volcano, Kyushu, Japan, Based on Resistivity and Self-Potential Survey Results. Geothermics, 32, 21-46, 2003

Zogala, B., Mendecki, Maciej J., M. Zuberek, W., Robak, M. Application of SelfPotential Method in The Area Contaminated with Oil Derivatives. Acta Geodyn. Geomater., Vol. 9, No. 2 (166), 179-189, 2012

Ye Zhang. Groundwater Flow and Solute Transport Modeling. University of Wyoming. 2011

Polycarpou,. C. Anastasia. 2006. An Introduction to The Finite Element Method in Electromagnetism. Morgan \& Claypool Publisher: USA
Yasukawa, K., Andan, A., Kusuma, D. S., Uchida, T. Self-Potential in The Mataloko Geothermal Prospect, Flores, Indonesia. Proceedings World Geothermal Congress 2000, KyusuTohoku, Japan, May 28-June 10, 2000

Nourbehecth, B. Irreversible Thermodynamics Effect in Inhomogeneous Media and Their Aplication in Certain Geoelectric Problems. $121 \mathrm{pp}$

Jardani, A., Revil, A., Akoa, F., Schmutz, M., Florsch, N., Dupont, J. P. Least Squares Inversion of Self-Potential (SP) Data And Aplication to The Shallow Flow of Ground Water in Sinkholes. Geophysical Research Letters, Vol. 33, L19306, doi: 10.1029/2006GL027458, 2006

Jardani, A., Revil, A., Bdere, A.,Crespy, A., Dupont, J. P, Barrash, and Malawa. Tomography of The Darcy Velocity from Self-Potential Measurement. Geophysical Research Letters, Vol. 34, L24403, doi: 10.1029/2007GL031907, 2007

Rausch, Randolf. Groundwater Modeling An Introduction To Groundwater Flow And Solute Transport Modeling With Application. Technische Universitat Darmstadt, 2009

Reynolds, Jhon M. An Introduction to Applied an Environmental Geophysics. John Wiley and Sons: New York 